\title{
Simultaneous Determination of Plasma Lactate, Pyruvate, and Ketone Bodies following tert-Butyldimethylsilyl Derivatization using GC-MS-SIM
}

\author{
Hye-Ran Yoon ${ }^{\dagger}$ \\ Biomedical \& Pharmaceutical Analysis Lab, College of Pharmacy, Duksung Women's University, \\ Seoul 01369, Korea
}

\begin{abstract}
Lactate and ketone bodies are considered biological markers for ketosis and several inherited metabolic disorders. In the current study, the specific ratios of lactate and ketone bodies as analytical tools for differential diagnosis of various lactic acidosis were devised. The study included a protein precipitation step following tert-butyldimethylsilyl derivatisation. Total run time was approximately $30 \mathrm{~min}$ including sample preparation and GS/MS analysis. The limits of detection were below $0.1 \mathrm{pg} / \mathrm{mL}$ over the targeted 4 analytes. The calibration curve was linear over the concentration range of 0.001 $250 \mu \mathrm{g} / \mathrm{mL}$ for pyruvate, beta-hydroxybutyrate, and acetoacetate $\left(\mathrm{R}^{2}>0.99\right)$. Inter-day accuracy and precision were $87.7 \sim 94.8 \%$ with RSD of $2.5 \sim 5.7 \%$ at 2 levels. Absolute recoveries (\%) of target analytes were $87.0 \sim 98.4 \%$. The method was validated for the quantification of lactate and ketone bodies for differentiation of lactic acidosis.
\end{abstract}

Key Words: Lactate, Pyruvate, Beta-hydroxybutyrate, Acetoacetate, tert-butyldimethylsilylation

\section{INTRODUCTION}

Lactic acidosis is presented from various etiologies including primary lactic acidosis and secondary to acquired conditions such as infections, severe catabolic state, tissues anoxia, poisoning etc. Therefore, the differential diagnosis of lactatemia is imperative to properly manage patients with different origins of lactic acidosis. In particular, determinations of the ratio of lactate to pyruvate, 3-hydroxybutyrate to acetoacetate are the most informative measurements in differentiation of various origins of lactic acidosis. Lactic acidosis is a form of metabolic acidosis due to the inadequate clearance of lactate from the blood. Lactate is a

* Received: December 15, 2015 / Revised: December 28, 2015

Accepted: December 28, 2015

${ }^{\dagger}$ Corresponding author: Hye-Ran Yoon. Lab of Biomedical \& Pharmaceutical Analysis, College of Pharmacy, Duksung Women's University, Ssangmundong 419, Dobong-gu, Seoul 01369, Korea.

Tel: +82-2-901-8387, Fax: +82-2-901-8164 e-mail: hyeran11@ds.ac.kr

(C)The Korean Society for Biomedical Laboratory Sciences. All rights reserved. byproduct of anaerobic respiration and is normally cleared from the blood by the liver, kidney and skeletal muscle (Fig. 1). Lactic acidosis occurs when the body's buffering system is overloaded and tends to cause a $\mathrm{pH}$ of $\leq 7.25$ with plasma lactate $\geq 5 \mathrm{mmol} / \mathrm{L}$. It is usually caused by a state of tissue hypoperfusion and/or hypoxia. This causes pyruvate to be preferentially converted to lactate during anaerobic respiration (Vassault et al., 1991). Hyperlactatemia is defined as plasma lactate $>2 \mathrm{mmol} / \mathrm{L}$. Any other cause of metabolic acidosis, particularly those due to diabetic ketoacidosis, other organic acidosis, chronic kidney disease, alcoholic ketoacidosis, hyperosmolar hyperglycaemic non-ketotic coma, and poisoning or drug toxicity (Lee et al., 1991; Shimizu et al., 2012).

A series of lactate assays have been reported for lactate. The ELISA assay has been the representative method for years in myocardial blood or plasma (Slamet et al., 1991; Levy et al., 2000; Shinde et al., 2005; Vogel et al., 2008; Kapoor et al., 2011). Other assays have been developed such as enzyme assay (Lennart et al., 1963), semi-automatic blood 


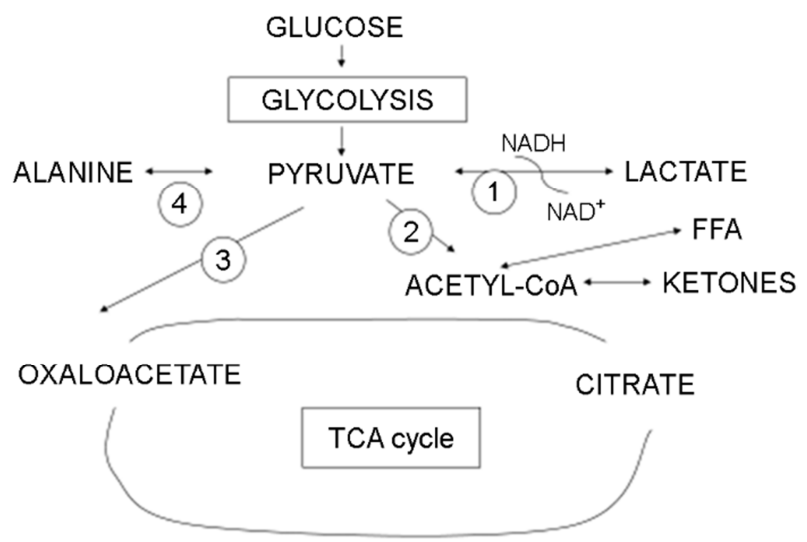

Fig. 1. Metabolic sources and fates of pyruvate; 1, lactate dehydorgenase; 2, pyruvate dehydorgenase complex; 3 , pyruvate carboxylase; 4 , alanine aminotransferase.

FIA assay (Karlsson et al., 1983), and automated enzyme assay with Hitachi automatic analyzer 911 (Lorenz et al., 2003). Assays for pyruvate have been reported such as a sensitive fluorometric assay (Zhua et al., 2010) enzymic fluorometric continuous-flow assays (Lloyd et al., 1978), radioisotopic assay (Constantin-Teodosiu et al., 1991) and serum $\mathrm{H}_{1}$ NMR assay (Amathieu et al., 2014). Although ketone bodies have been studied for decades, more sensitive analytical methods are needed with high selectivity and specificity. Head-space gas chromatography has been applied in several cases for indirect determination of beta-hydroxy butyrate (BHB) in plasma and blood samples (Kimura et al., 1985; Felby et al., 1994; Holm et al., 2010). GC-MSD derivatization has also been reported for the determination of BHB in blood and plasma (Nissen et al., 1990; Hassan et al., 2009; Elliott et al., 2010; Hur et al., 2014). Liquid chromatography using enzymatic oxidation followed by UV tandem mass spectrometry has also been developed (Yamato et al., 2009; Dahl et al., 2012). LC with common reverse phases is quite difficult where polar beta-hydroxy butyrate shows poor retention on stationary phase, thus direct determination of lactate and pyruvate is still difficult when present at low concentrations (Bhattacharya et al., 1995; Villas-Boas et al., 2005). Here, in this study, a method for simultaneous determination of lactate, pyruvate and ketone bodies followed by TBDMS derivatization (Chaves et al., 1987; Hoffeman et al., 1989) in GC-MS-SIM is described.

\section{MATERIAL AND METHODS}

\section{Chemicals and apparatus}

Lactate, pyruvate, beta-hydroxy butyrate and acetoacetate were obtained from Sigma-Aldrich (MO, USA) as chromatographic standards. All other chemicals and organic solvents including acetonitrile and methanol were purchased from J. T. Baker or YAKURI Pure Chemical Co. LTD (Osaka, Japan) as chromatograhic grade. MTBSTFA (Ntert-butyldimethylsilyl-N-methyltrifluoroacetamide) as a derivatisation reagent and 2-ketocaproic acid (internal standard, ISTD) were obtained from Sigma-Aldrich (MA, USA). Distilled water was purchased from Millipore-Milli $\mathrm{QT}^{\mathrm{M}}$. Thermo vap (TAITEC model DTU-2C) (Tokyo, Japan) was used for evaporation as well as derivatization. Shaker (TAITEC, Tokyo, Japan) and centrifuge (Eppendorf model 5424) (Hamburg, Germany) were used for mixing the specimens. Aliquots $(5 \sim 250 \mu \mathrm{L})$ of the standard solution were transferred into $1 \mathrm{~mL}$ PTFE-lined screw-capped derivatization vials.

\section{Specimens}

Plasma specimens from healthy individuals were used for method validation and were obtained from the Seoul Medical Science Institute. Plasma samples used in the validation study were collected in sodium citrate tubes (Duksan, Seoul, Korea) containing 3.2\% citrate. Pooled control plasmas were subjected to the same sample preparation procedure.

\section{Standards}

Separate stock solutions of lactate, pyruvate, beta-hydroxy butyrate, acetoacetate and IS were prepared by dissolving in methanol $(1,000 \mu \mathrm{g} / \mathrm{mL})$ and stored at $-20^{\circ} \mathrm{C}$ until used. Each stock solution was stored in a refrigerator until analysis. The stock solution was further diluted with methanol as working solutions.

\section{Gas chromatography mass spectrometry}

GC-MS was performed using Hewlett-Packard-6890 Series II GC-MS system (PA, USA) consisting of a Model 
$6890 \mathrm{~N}$ gas chromatograph, a Model 5973N mass-selective detector (a HP Hewlett-Packard 3365 MSD Chemstation) and a Model 7683 series injector. An HP-5 Column (30 m $\times 0.25 \mathrm{~mm}$ I.D., $0.25 \mu \mathrm{m})$ was purchased from Agilent Technologies. Helium gas set to flow-rate of $0.8 \mathrm{~mL} / \mathrm{min}$ was used as a carrier gas. The GC oven temperature was programmed from $120^{\circ} \mathrm{C}$ ( 2 min hold) to $300^{\circ} \mathrm{C}$ at a rate of $10^{\circ} \mathrm{C} / \mathrm{min}$ with a total run time of $13.5 \mathrm{~min}$. The temperature of inlet and the interface were $280^{\circ} \mathrm{C}$ and $300^{\circ} \mathrm{C}$, respectively. The MS was executed in selected ion monitoring (SIM) mode with dwell time of $100 \underline{\mathrm{ms}}$. $[\mathrm{M}]^{+}$was selected as conformation ion $(\mathrm{CI})$ and the ion with highest abundance was chosen as quantification ion (QI). One $\mu \mathrm{L}$ aliquot of the final derivative was injected into the GC-MS ion source in splitless mode.

\section{Extraction and derivatisation with tert-butyldimethyl- silylation}

A $200 \mu \mathrm{L}$ volume of plasma was transferred to a disposable $2 \mathrm{~mL}$ eppendorf tube and then $600 \mu \mathrm{L}$ of methanol were added. The mixed components were mixed gently after each addition. Shortly thereafter, the tube was immediately closed and vigorously vortex-mixed for a few seconds for protein precipitation. The mixture was then centrifuged at $5,000 \mathrm{rpm}$ at room temperature for $5 \mathrm{~min}$. To a $100 \mu \mathrm{L}$ of plasma supernatant, $200 \mu \mathrm{L}$ of ISTD solution was added. Sodium chloride was added until saturation. Two $\mathrm{mL}$ of ethylacetate was added as an extraction solvent and then extracted twice. The combined extract was treated with sodium sulfate and finally evaporated to dryness at $80^{\circ} \mathrm{C}$ with a gentle stream of nitrogen. To the dry residue of organic layer of extract were added of $20 \mu \mathrm{L}$ of MTBSTFA, $20 \mu \mathrm{L}$ of $1 \%$ trimethylamine, and $25 \mu \mathrm{L}$ of acetonitrile and then heated at $60^{\circ} \mathrm{C}$ for $30 \mathrm{~min}$. After cooling to room temperature, aliquots of the solution containing derivatives were used directly for GC-MS.

\section{Linearity and sensitivity}

Calibration curves were plotted by the peak area ratio of combined analyte solution to ISTD solution over the each analyte concentration using pooled control plasmas (100 $\mu \mathrm{L})$ spiked at various concentrations. The concentration of spiked to plasmas were $0.001,0.01,0.1,1,10,100,200$, 250 and $500 \mu \mathrm{g} / \mathrm{mL}$ for the working solution. ISTD solution was added ( $50 \mu \mathrm{L}$ of $100 \mathrm{ng} / \mu \mathrm{L})$ to plasmas. The limit of detection (LOD) was calculated where the $\mathrm{S} / \mathrm{N}$ ratio was greater than 3 and the limit of quantitation (LOQ) was greater than 10. The LOQ was validated with the lowest concentration where the each analyte could be quantified with acceptable accuracy $(<20 \%)$ and precision $(<20 \%$ $\mathrm{CV})$. The LOQ was confirmed by the inclusion of the lowest concentration in the range of the calibration curves.

\section{Validation}

Matrix matched calibrations were based on pooled plasma and were treated using the developed procedure. A blank sample (i.e., processed sample without any added analyte) and a sample spiked only with ISTD were also included. Accuracy was determined as the ratio of back-calculated value to the nominal standard concentration and precision as the $\% \mathrm{CV}$ of peak areas from replicate analyses for intraday $(n=3)$ and for inter-day $(n=3)$. Accuracy was calculated as: [measured concentration] / [nominal concentration] $X$ $100 \%$. The recovery was determined by calculating the

Table 1. Mass fragmentation and selected ions for the determination by GC-MS

\begin{tabular}{|c|c|c|c|c|c|c|}
\hline \multirow{2}{*}{ Compounds } & \multirow{2}{*}{ Retention time } & \multirow{2}{*}{ F.M. } & \multirow{2}{*}{$\mathrm{M}^{+}$} & QI & $\mathrm{CI}$ & \multirow{2}{*}{ Other ions } \\
\hline & & & & $(\mathrm{M}-57)^{+}$ & $(\mathrm{M}-159)^{+}$ & \\
\hline Lactate & 6.96 & 90 & 320 & 263.1 & 161.1 & $261.1,259.1$ \\
\hline Pyruvate & 7.45 & 88 & 318 & 261.1 & 159.1 & $261.1,259.2$ \\
\hline Beta-hydroxy butyrate & 8.19 & 104 & 334 & 277.1 & 175.1 & $275.1,159.1$ \\
\hline Acetoacetate & 9.41 & 102 & 332 & 275.1 & 173.1 & $303.1,301.1$ \\
\hline
\end{tabular}


Table 2. Precision, accuracy and recoveries for intra-, inter-day assay

\begin{tabular}{|c|c|c|c|c|c|c|c|c|}
\hline \multirow[b]{2}{*}{ Analytes } & \multirow{2}{*}{$\begin{array}{c}\text { Conc. } \\
(\mu \mathrm{g} / \mathrm{mL})\end{array}$} & \multicolumn{3}{|c|}{ Intra-day $(\mathrm{n}=3)$} & \multicolumn{3}{|c|}{ Inter-day $(n=3)$} & \multirow{2}{*}{$\begin{array}{c}\text { Recoveries } \\
(\mathrm{n}=3, \%)\end{array}$} \\
\hline & & $\begin{array}{c}\text { Mean } \\
(\text { Conc. } \pm \mathrm{SD})\end{array}$ & $\begin{array}{l}\text { Precision } \\
\text { RSD (\%) }\end{array}$ & $\begin{array}{c}\text { Accuracy } \\
(\%)\end{array}$ & $\begin{array}{c}\text { Mean } \\
\text { (Conc. } \pm \mathrm{SD})\end{array}$ & $\begin{array}{l}\text { Precision } \\
\text { RSD (\%) }\end{array}$ & $\begin{array}{c}\text { Accuracy } \\
(\%)\end{array}$ & \\
\hline \multirow{2}{*}{ Lactate } & 1 & $1.1 \pm 0.2$ & 3.4 & 87.2 & $1.2 \pm 0.3$ & 3.2 & 88.7 & 87.0 \\
\hline & 10 & $10.3 \pm 1.7$ & 3.2 & 89.8 & $10.5 \pm 2.1$ & 2.5 & 94.8 & 95.2 \\
\hline \multirow{2}{*}{ Pyruvate } & 1 & $0.9 \pm 0.1$ & 5.2 & 98.2 & $1.4 \pm 0.2$ & 5.7 & 92.7 & 98.3 \\
\hline & 10 & $9.9 \pm 2.6$ & 4.9 & 99.2 & $10.6 \pm 1.8$ & 4.6 & 90.5 & 97.9 \\
\hline \multirow{2}{*}{$\begin{array}{l}\text { Beta-hydroxy } \\
\text { butyrate }\end{array}$} & 1 & $0.9 \pm 0.2$ & 4.4 & 94.6 & $1.3 \pm 0.2$ & 4.2 & 89.6 & 89.9 \\
\hline & 10 & $8.9 \pm 1.5$ & 4.6 & 100.6 & $11.2 \pm 1.9$ & 4.8 & 88.2 & 91.3 \\
\hline \multirow{2}{*}{ Acetoacetate } & 1 & $0.9 \pm 0.1$ & 4.9 & 87.2 & $0.9 \pm 0.2$ & 5.2 & 87.7 & 97.6 \\
\hline & 10 & $9.5 \pm 1.7$ & 5.2 & 89.6 & $9.8 \pm 1.8$ & 4.4 & 91.5 & 98.4 \\
\hline
\end{tabular}
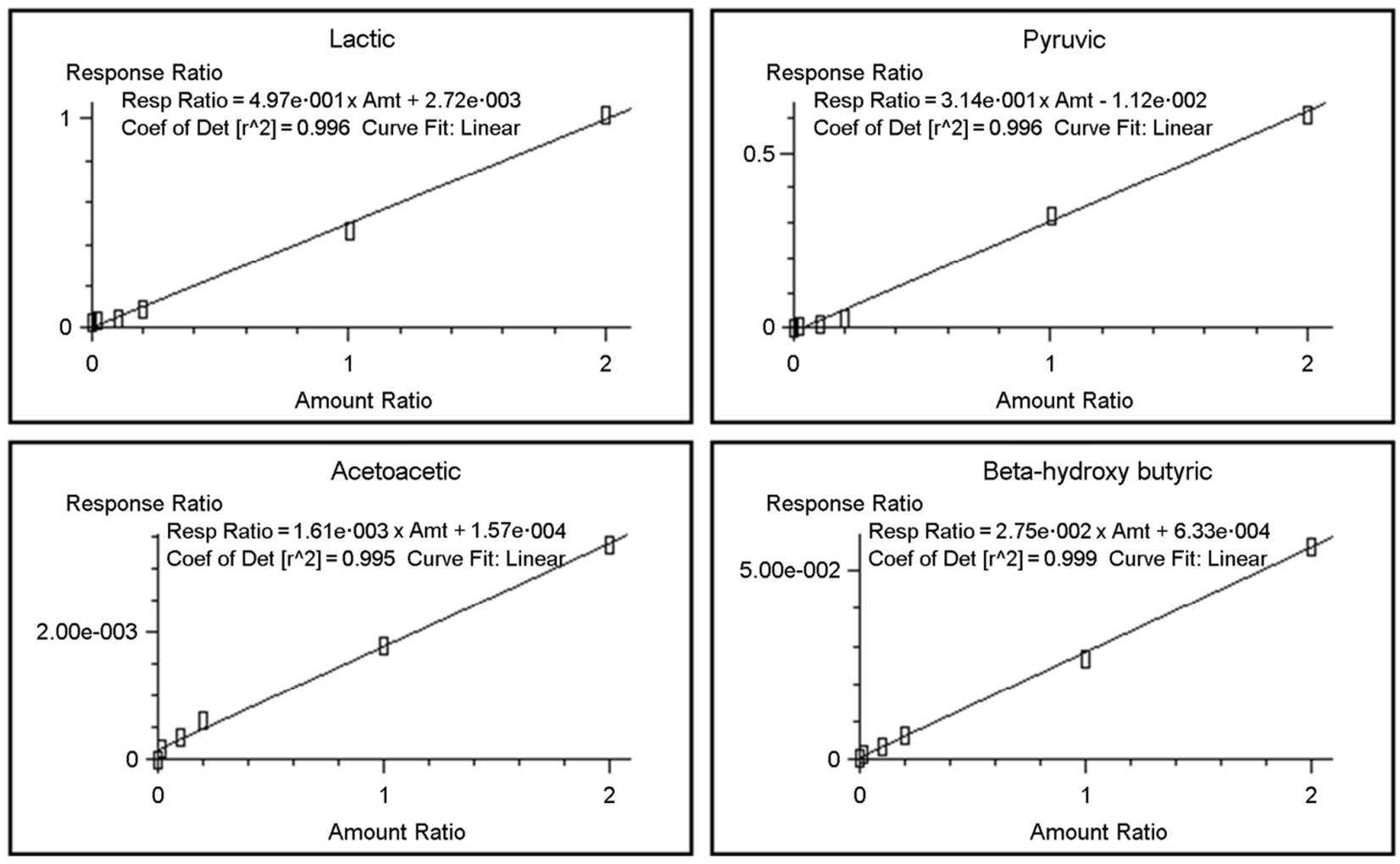

Fig. 2. Calibration curves of lactate, pyruvate, beta-hydroxybutyrate and acetoacetate.

concentration of extracted and non-extracted spiked samples at low and medium levels of concentration $(1 \mu \mathrm{g} / \mathrm{mL}$ and $10 \mu \mathrm{g} / \mathrm{mL})$. Carryover effect was evaluated from the proof data that six blank samples were run without any residual peak after running 50-folder high concentration of 4 analytes.

\section{RESULTS AND DISCUSSION}

\section{Extraction and clean-up}

The standard spiked pooled plasmas were subjected by 
protein precipitation using methanol. Lactate, pyruvate and ketone bodies were extracted twice with ethylacetate including moisture trapping step with sodium acetate. The combined clean-up procedures removed most of the plasma matrix with protein precipitation, moisture trapping and ethylacetate extraction.

\section{GC-MS SIM ion and chromatogram}

The mass spectrum was obtained at electron impact ionization mode in full scan with a scan range from 50 to $550 \mathrm{~m} / \mathrm{z}$. Molecular ion and other fragmentation ions were conformed concurrent with library matching (Table 1 ). The TBDMS derivatives of lactate, pyruvate and ketone bodies, had very typical EI mass spectra at $70 \mathrm{eV}$ dominated by diagnostic ions. All spectra had a base peak m/z 73. A weak molecular ion or more often a weak (M-15) ${ }^{+}$ion was present in most instances. The most important characteristic of the spectra is the presence of intense (M-57) ${ }^{+}$ion and (M-159) ${ }^{+}$ ion which corresponded to tert-butyl group and cleavage at the $\alpha$-carbon atom (M-COO $\mathrm{TBDMS}^{+}$, respectively.

Table 1 shows mass fragment found and ions selected for selected ion monitoring mode. Formula weight (FW), $[\mathrm{M}]^{+},(\mathrm{M}-57)^{+},(\mathrm{M}-159)^{+}$ions, and retention time were evaluated for selected ion monitoring mode. The (M-57) ${ }^{+}$ as quantitation ion (QI) was chosen that has maximum intensity in the spectra. The $(\mathrm{M}-159)^{+}$has been chosen as confirmation ion (CI). The confirmation of each analyte was based on the presence of the co-elution of selected ion species, as well as the ratios of CI versus QI. The ratio of their peak intensity $(\mathrm{QI} / \mathrm{CI})$ was considered an another important

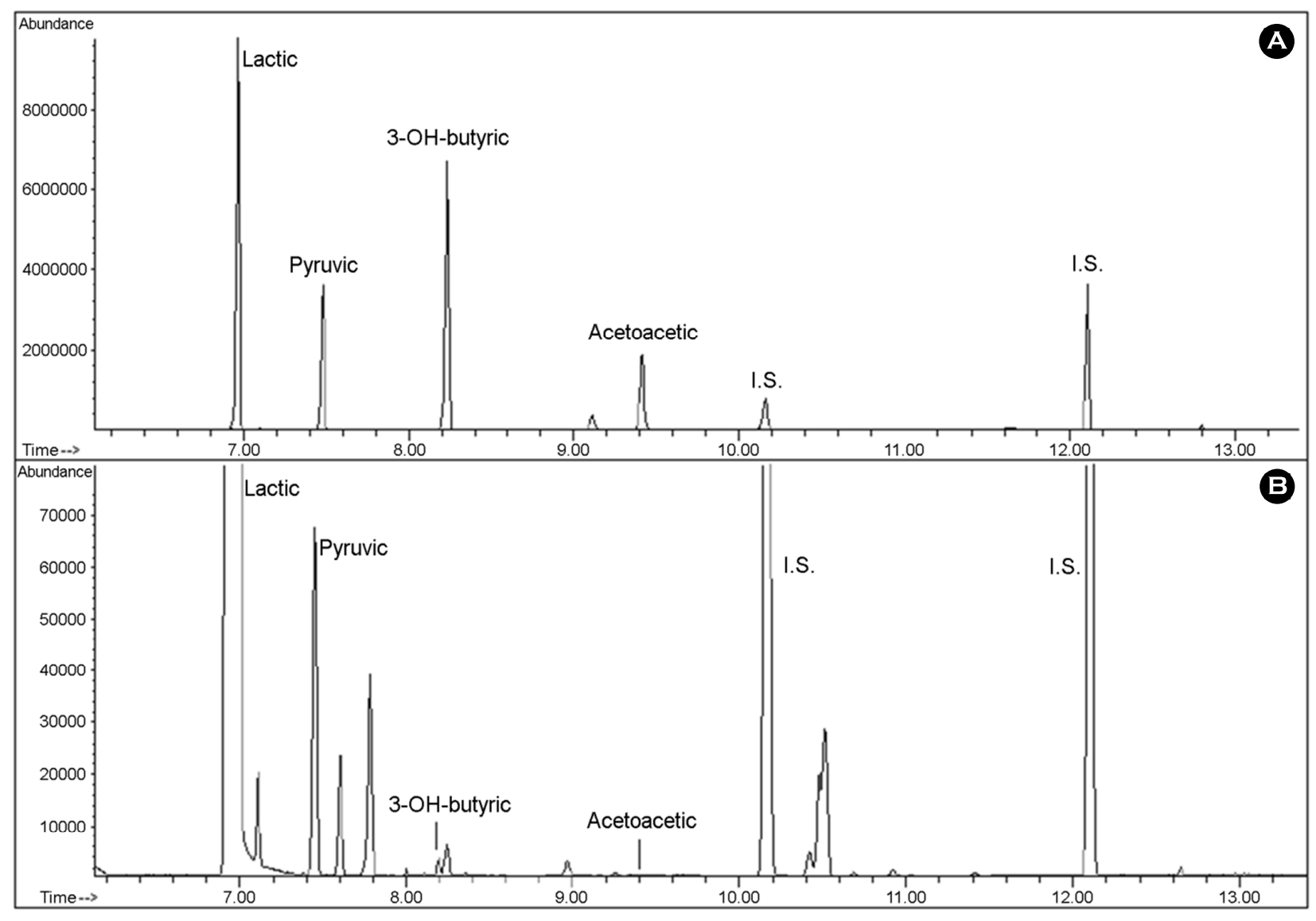

Fig. 3. GC-MS chromatogram of lactate, pyruvate, beta-hydroxy butyrate, and acetoacetate following TBDMS (A) standard solutions, (B) plasma with lactic acidosis 
parameter used for identification. Chromatogram of the TBDMS derivatives was confirmed by obtaining the data in full scan mode with a scan range from $\mathrm{m} / \mathrm{z} 50$ to 550 (Fig. 3A).

\section{Validation}

Linear dynamic range was linear over the range of $1.0 \mathrm{ng} /$ $\mathrm{mL}$ to $250 \mu \mathrm{g} / \mathrm{mL}$ for pyruvate $\left(\mathrm{R}^{2}=0.996\right)$, beta-hydroxy butyrate $\left(\mathrm{R}^{2}=0.999\right)$, acetoacetate $\left(\mathrm{R}^{2}=0.995\right)$ and $1.0 \mathrm{ng} /$ $\mathrm{mL}$ to $200 \mu \mathrm{g} / \mathrm{mL}$ for lactate $\left(\mathrm{R}^{2}=0.996\right)$ (Fig. 2). The limit of detections (LODs) and limit of quantifications (LOQs) for the extraction process was determined as $0.8 \sim 1 \mathrm{ng} / \mu \mathrm{L}$ corresponding to a peak - to peak signal to noise ratio $(\mathrm{S} / \mathrm{N})$ of 3 and 10, respectively. For carry over effect, six separate blank samples run after the high concentration of 4 analytes demonstrated no clear visible peak indicating no carryover effect demonstrating the integrity of validation. According to the method validation guidelines, the precision and accuracy within RSD of $\pm 15 \%$ maintained the validation integrity of the method. Absolute mean recoveries of extraction $(n=3)$ was $87.0 \sim 98.4 \%$ (Table 2). For general screening purposes, the accepted ranges of recoveries are more than $60 \%$. Thus recoveries of the developed analytical method are appropriate enough for screening and differential diagnosis purpose. The developed GC-MS SIM method was then applied to a human plasma sample with lactic acidosis. Fig. 3B shows representative GC-MS SIM chromatograms of lactate, pyruvate and ketone bodies standard and plasma with lactic acidosis. From these results, the study demonstrated the possibility of application for differential diagnosis of lactic acidosis using GC-MS/SIM (Yamushi et al., 2003).

To the best of my knowledge, this is the first report of simultaneous determination of these four compounds following TBDMS in Korea.

In conclusion, a sensitive analytical method was developed for the determination of lactate, pyruvate and ketone bodies by GC-MS/SIM without expensive and tedious solid phase extraction (SPE) step. Without SPE, the newly developed method effectively determined four analytes under a simple sample preparation within a 13 min chromatographic separation. The method was successfully validated and applied to a human plasma sample.

\section{Acknowledgements}

This study was supported by a research grant 2015 from Duksung Women's University, Seoul, Korea.

\section{Conflict of interest}

The author has no potential conflicts of interest relevant to this article to report.

\section{REFERENCES}

Amathieu R, Triba MN, Nahon P, Bouchemal N, Kamoun W, Haouache H, Trinchet JC, Savarin P, Le Moyec L, Dhonneur G. Serum ${ }^{1} \mathrm{H}-\mathrm{NMR}$ metabolomic fingerprints of acute-onchronic liver failure in intensive care unit patients with alcoholic cirrhosis. PLoS One. 2014. 19: e89230.

Bhattacharya M, Fuhrman L, Ingram A, Nickerson KW, Conway T. Single-run separation and detection of multiple metabolic intermediates by anion-exchange high-performance liquid chromatography and application to cell pool extracts prepared from Escherichia coli. Anal Biochem. 1995. 232: 98-106.

Chaves Das Heves, Vasconceios AM. Capillary gas chromatography of amino acids, including asparagine and glutamine: sensitive gas chromatographic-mass spectrometric and selected ion monitoring gas chromatographic-mass spectrometric detection of the N,O(S)-tert-butyldimethylsilyl derivatives. J Chromatogr. 1987. 392: 249-258.

Constantin-Teodosiu D, Cederblad G, Hultman E. A sensitive radioisotopic assay of pyruvate dehydrogenase complex in human muscle tissue. Anal Biochem. 1991. 198: 347-351.

Dahl SR, Olsen KM, Strand DH. Determination of gamma-hydroxy butyrate (GHB), beta-hydroxybutyrate (BHB), pregabalin, 1,4butane-diol $(1,4 \mathrm{BD})$ and gamma-butyrolactone $(\mathrm{GBL})$ in whole blood and urine samples by UPLC-MSMS. J Chromatogr B 2012. 885: 37-42.

Elliott S, Smith C, Cassidy D. The post-mortem relationship betwee betahydroxybutyrate (BHB), acetone and ethanol in ketoacidosis. Forensic Sci Int. 2010. 198: 53-57.

Felby S, Nielsen E. Determination of ketone bodies in postmortem blood by headspace gas chromatography. Forensic Sci Int. 1994. 64: 83-88.

Hassan HMA, Cooper GAA. Determination of $\beta$-hydroxybutyrate in blood and urine using gas chromatography-mass spectrometry. J Anal Toxicol. 2009. 33: 502-507.

Hoffmann G, Aramak S, Blum-Hoffmann E, Nyhan WL, Sweetman 
L. Quantitative analysis for organic acids in biological samples: batch isolation followed by gas chromatographic-mass spectrometric analysis. Clin Chem. 1989. 35: 587-595.

Holm KMD, Linnet K, Rasmussen BS, Pedersen AJ. Determination of ketone bodies in blood by headspace gas chromatographymass spectrometry. J Anal Toxicol. 2010. 34: 549-554.

Hur H, Paik MJ, Xuan Y, Nguyen DT, Ham IH, Yun J, Cho YK, Lee G, Han SU. Quantitative measurement of organic acids in tissues from gastric cancer patients indicates increased glucose metabolism in gastric cancer. PLoS One. 2014. 9: e98581.

Kapoor P, Mandal B, Chowdhury U, Singh S, Kiran U. Changes in myocardial lactate, pyruvate and lactate-pyruvate ratio during cardiopulmonary bypass for elective adult cardiac surgery: Early indicator of morbidity. J Anaesthesiol Clin Pharmacol. 2011. 27: 225-232.

Karlsson J, Jacobs I, Sjödin B, Tesch P, Kaiser P, Sahl O, Karlberg B. Semi-automatic blood lactate assay: experiences from an exercise laboratory. Int J Sports Med. 1983. 4: 52-55.

Kimura M, Kobayashi K, Matsuoka A, Hayashi K. Head-space gas-chromatographic determination of 3-hydroxybutyrate in plasma after enzymatic reactions, and the relationship among the three ketone bodies. Clin Chem. 1985. 31: 596-598.

Lee K, Berthiaume F, Stephanopoulos GN, Yarmush ML. Metabolic flux analysis: a powerful tool for monitoring tissue function. Tissue Eng. 1999. 5: 347-368.

Lennart Lundholm, Ella Mohme-Lundholm and Nandor Vamos Lactic Acid Assay with L(+)lactic Acid Dehydrogenase from Rabbit Muscle. Acta Physiol Scand. 1963. 58: 243-249.

Levy B, Sadoune LO, Gelot AM, Bollaert P, Nabet PG, Larcan A. Evolution of lactate/pyruvate and arterial ketone body ratios in the early course of catecholamine-treated septic shock. Crit Care Med. 2000. 28: 114-119.

Lloyd B, Burrin J, Smythe P, Alberti KG. Enzymic fluorometric continuous-flow assays for blood glucose, lactate, pyruvate, alanine, glycerol, and 3-hydroxybutyrate. Clin Chem. 1978. 24: 1724-1729.

Lorenz, I. Hartmann, A. Gentile Determination of D-lactate in calf serum samples - an automated enzymatic assay. Comp Clin Path. 2003. 12: 169-171.

Nissen S, Van Koevering M, Webb D. Analysis of $\beta$-hydroxy$\beta$-methyl butyrate in plasma by gas chromatography and mass spectrometry. Anal Biochem. 1990. 188: 17-19.

Shimizu I, Ishikawa E, Fukuda T, Okazaki S. Blood glucose, urinary glucose, blood ketone bodies, urine ketone bodies, blood lactic acid, and blood pyruvic acid. Nihon Rinsho. 2012. 70: 433-437.

Shinde S, Golam K, Patil ND, Kumar P. Perioperative blood lactate levels, pyruvate levels and lactate-pyruvate ratio in children undergoing cardiopulmonary bypass for congenital heart disease. Indian J Crit Med. 2005. 9: 145-150.

Slamet T, Lim PKC, Mak JW, Storey J, Noor RA. Sensitivity of Malaysian isolates of Plasmodium falciparum to a number of antimalarials using the WHO in vitro micro test. Tropical Biomedicine. 1991. 8: 85-87.

Vassault A, Bonnefont JP, Specola N, Saudubray JM. Lactate, pyruvate, and ketone bodies. In Techniques in Diagnostic Human Biochemical Genetics - a Laboratory Manual, Hommes FA(ed.). New York: Wiley-Liss. 1991: 28-86.

Villas-Boas SG, Mas S, Akesson M, Smedsgaard J, Nielsen J. Mass spectrometry in metabolome analysis. Mass Spectrom Rev. 2005. 24: 613-646.

Vogel C, Wessel E, Siesler H. W. FT-IR imaging spectroscopy of phase separation in blends of poly(3-hydroxybutyrate) with poly(L-lactic acid) and poly(epsilon-caprolactone). Biomacromolecules. 2008. 9: 523-527.

Yamato S, Shinohara K, Nakagawa S, Kubota A, Inamura K, Watanabe G, Hirayma S, Miida T, Ohtas. High performance liquid chromatography determination of ketone bodies in human plasma by derivatization with p-nitrobenzene diazonium fluoroborate. Anal Biochem 2009. 384: 145-150.

Yarmush ML, Banta S. Metabolic engineering: Advances in modeling and intervention in health and disease. Annu Rev Biomed Eng. 2003. 5: 349-381.

Zhua A, Romerob R, Howard R. Pettya, A sensitive fluorimetric assay for pyruvate Anal Biochem. 2010. 396: 146-151. 